\title{
Study on Evaluation Method of Water Injection Efficiency in Low- Permeability Reservoir
}

\author{
Qiang Yu, ${ }^{1}$ Xinjie Wang, ${ }^{1}$ Yifei Wang, ${ }^{2}$ and Xingjiao Zhang $\mathbb{D}^{3}$ \\ ${ }^{1}$ No.2 Oil Production Plant, Changqing Oilfield, PetroChina, China \\ ${ }^{2}$ Hebei Huabei Oilfield Youxin Exploration and Development Service Co., Ltd., PetroChina Huabei Oilfield Company, China \\ ${ }^{3}$ Department of Petroleum Engineering, China University of Petroleum, Beijing 102249, China
}

Correspondence should be addressed to Xingjiao Zhang; 2018212128@student.cup.edu.cn

Received 10 October 2020; Accepted 23 April 2021; Published 26 May 2021

Academic Editor: Shun Liu

Copyright (C) 2021 Qiang Yu et al. This is an open access article distributed under the Creative Commons Attribution License, which permits unrestricted use, distribution, and reproduction in any medium, provided the original work is properly cited.

Low-permeability reservoirs, especially ultralow-permeability reservoirs, usually show a problem of ineffective water injection which leads to low pressure with high injection-production ratio. It is urgent to determine the direction and proportion of ineffective water injection, so as to guide the adjustment of water injection development. Based on the theory of percolation mechanics and combined with the modern well test analysis method, the determination method of effective water injection ratio was established. This method can not only judge the direction of injected water but also determine the proportion of invalid injected water. This method was applied on typical oil reservoirs; the evaluation results showed that extremely low permeability and ultralow permeability usually exist the situation of water holding around the injected well which is almost $20 \%$ of the injected water. Some areas existed the water channeling; the evaluation results showed that the water channeling was closely related with sedimentary microfacies rather than microfractures, and the invalid injection accounts are about $45 \%$ of the injected water. The method is simple and feasible, which can provide technical reference for the development strategy adjustment of water drive development in low-permeability reservoir.

\section{Introduction}

At present, low-permeability reservoirs, especially ultralow permeability, generally have the following two characteristics in water development. (1) High injection-production ratio, low reservoir pressure, and low water content. As shown in Figure 1, the reservoirs of Xifeng, Wangyao, Jilin 119, Jilin 228, Santanghu, Z8, and other reservoirs all showed the above problems. For ultralow-permeability reservoirs, the injection-production ratio is around 4, but the formation pressure is still decreasing. Where did the injected water go? (2) Medium and high injection-production ratio, good pressure maintenance level, and high water cut. Generally, this kind of reservoir has strong heterogeneity which is difficult to determine by traditional methods.

In this research, an evaluation method of water injection efficiency in low-permeability reservoir is established which is based on the percolation mechanics and modern well test analysis method.

\section{Evaluation Method of Water Flow Direction and Injection Water Utilization Rate in Low- Permeability Reservoir}

2.1. Evaluation Methods of Injection Water Utilization in Reservoirs with High Injection-Production Ratio, Low Formation Pressure, and Low Water Cut. The well test interpretation model of low-permeability reservoir is established. It combined with development parameters to determine the direction of injected water and the injection water utilization rate.

2.1.1. Establishment and Solution of Well Test Interpretation Model for Low-Permeability Reservoir. On the basis of the 


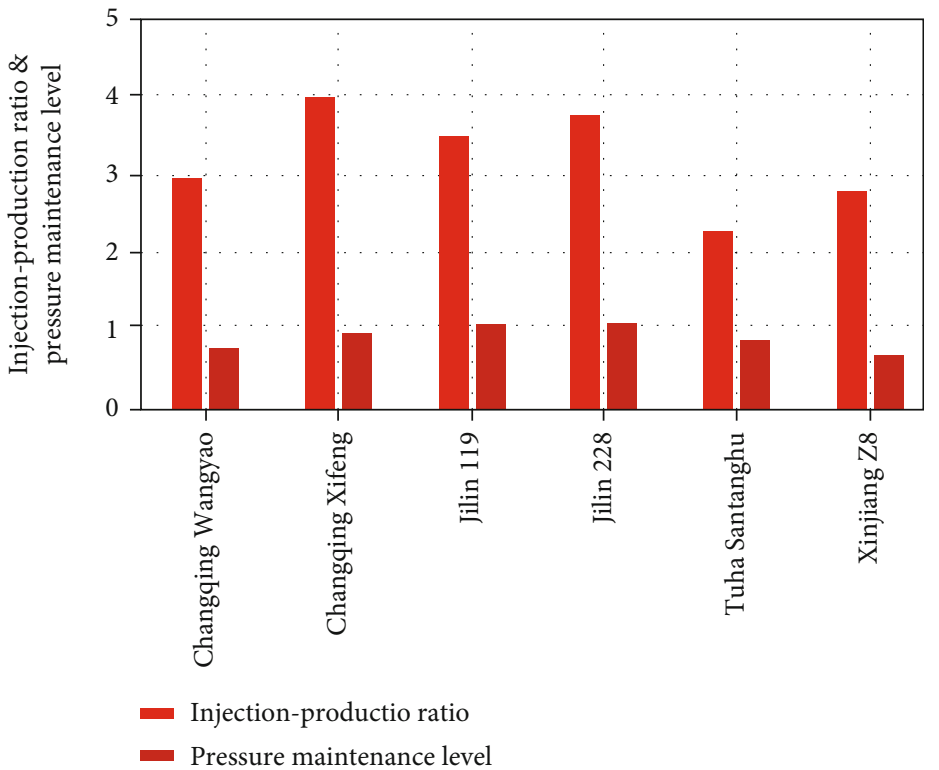

FIGURE 1: Injection-production ratio and pressure retention levels in typical reservoirs.

conventional well test model, a seepage mathematical model of low-permeability reservoir is established by considering stress sensitivity and complex fracture network. The solution of the model is achieved through perturbation transform and Laplace transform [1-5].

Mathematical model of seepage flow considering complex fracture network and stress sensitivity is shown as follows.

$$
\begin{gathered}
\frac{1}{r} \frac{\partial}{\partial r}\left(r \frac{\partial p}{\partial r}\right)+\alpha\left(\partial \frac{\partial p}{\partial r}\right)^{2}-\frac{\lambda}{r}=e^{\alpha\left(p_{i}-p\right)} \frac{\mu \phi c_{t}}{3.6 k} \frac{\partial p}{\partial t}, \\
\left.\left(10^{3} k h e^{\alpha\left(\left(p_{i}-p\right)\right)} / 1.842 B \mu\right) r(\partial p / \partial r-\lambda)\right|_{r \rightarrow 0}=q,\left.p\right|_{r \rightarrow \infty}=p_{i}, \\
\left.p\right|_{t=0}=p_{i} .
\end{gathered}
$$

Mathematical model of seepage flow with fracture network is shown as follows.

$$
\begin{gathered}
\frac{k_{f}}{\mu} \frac{\partial p^{2}}{\partial y^{2}}+\alpha \frac{k_{f}}{\mu}\left(\frac{\partial p}{\partial y}\right)^{2}+\frac{B q_{f}}{86.4 W_{f} h_{f}}=0, \\
\left.\frac{k_{f} h_{f} W_{f} e^{\alpha\left(p_{i}-p\right)}}{86.4 \mu} \frac{\partial p_{f}}{\partial y}\right|_{y \rightarrow y_{d}}=B q_{d}, \\
\left.p\right|_{t=0}=p_{i} .
\end{gathered}
$$

Perturbation transform and Laplace transform were used to solve the above model to obtain the expression formula of bottom hole pressure [6-9].

$$
p_{D}=-\frac{1}{\alpha_{D}} \ln \left(1-\alpha_{D} \zeta_{D}\right)
$$

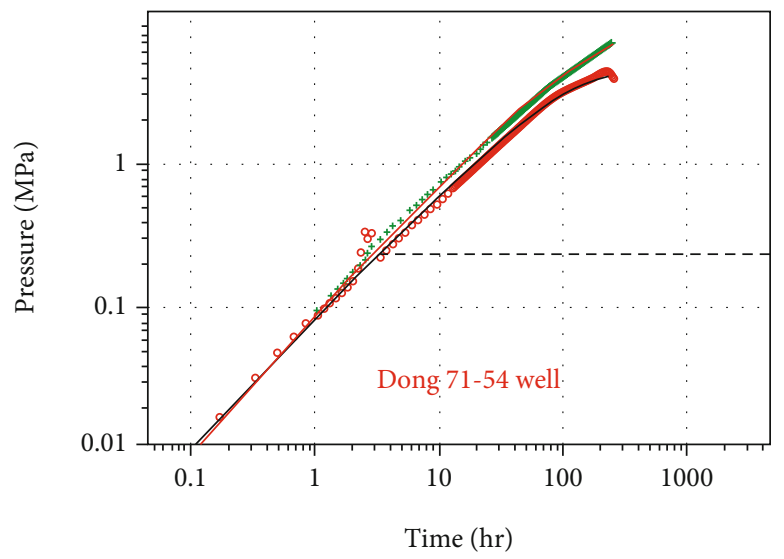

FIGURE 2: Characteristics of the well test curve in the middle stage of development.

Among them,

$$
\zeta_{D}=\zeta_{D 0}+\alpha_{D} \zeta_{D 1}+\alpha_{D}^{2} \zeta_{D 2}+o\left(\alpha_{D}^{2}\right)
$$

2.1.2. Analysis of Injection Dynamic Characteristics. Taking a typical oil injection well in Changqing Oilfield as an example, the well test curves at different times are shown in Figures 2 and 3. In the middle stage of development, the well test curve had a character of finite diversion curve (Figure 2). But the current well test curve had a character of composite reservoir (Figure 3). Almost 70\% injection well had above characteristics in this reservoir. Meanwhile, in the period of pressure drop test, the downhole pressure drop is small.

The injection data and production data proved that this type of well existed the situation of water holding around the injected well.

Based on the above analysis, it can be concluded that when the injection well meets the following characteristics: 


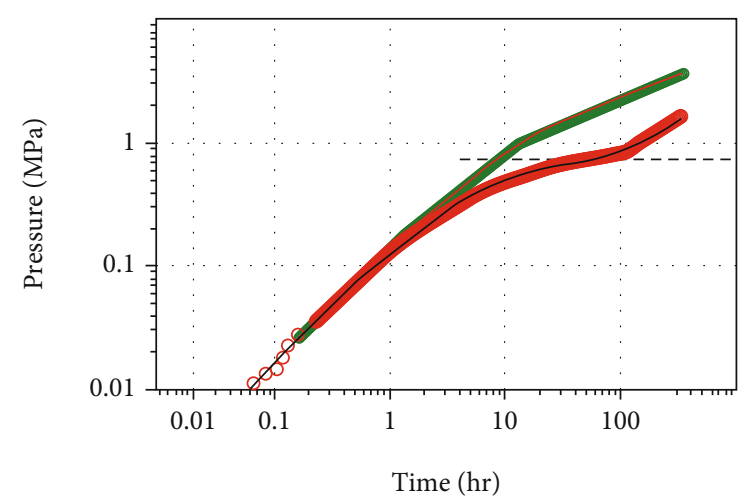

FIGURE 3: Current well test curve characteristics.

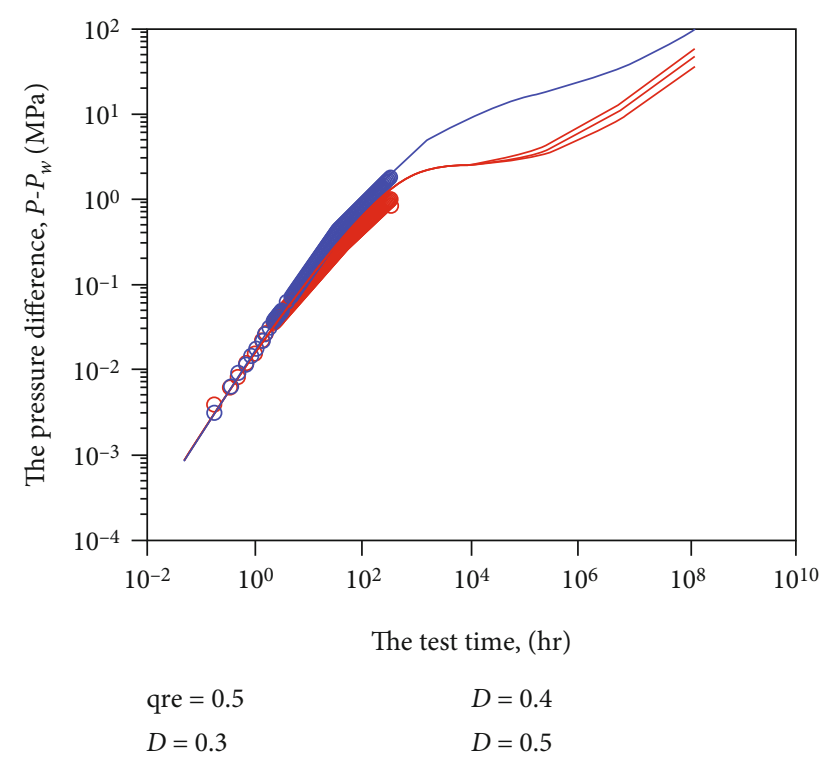

FIGURE 4: Fitting analysis of well test curves of typical wells.

(1) When injection is stopped, the pressure drop is small which indicated that the pressure diffusion of injected water is weak. (2) The injection pressure of the injection well is high and the injection volume drops which indicates the difficulty of water flow. (3) The well test curve shows the characteristics of the composite reservoir. When the above three rules are met, it can be determined that the injection water is not effectively swept and it is held around the injection well.

\subsubsection{Evaluation Method of Holding Water Volume. Based on} the above understanding, the well test interpretation model can be established to obtain wellbore, reservoir, and other parameters. The radius of the inner zone is the radius of holding water near the injection well which can be calculated by using the volumetric method.

The calculation formula of water storage capacity around the injected well is as follows:

$$
V=\pi * r^{2} * h * \varphi * y,
$$

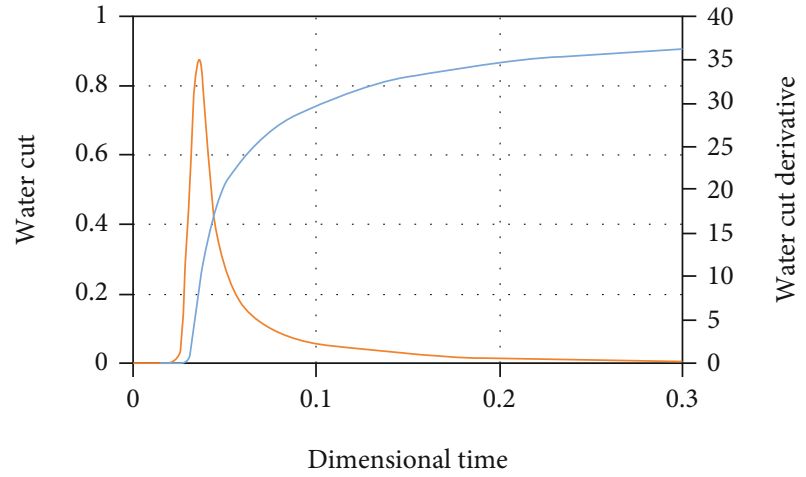

Water cut
- Water cut derivative

FIGURE 5: Water cut and its derivative curve with dimensionless time when there is no high-water-consumption zone.

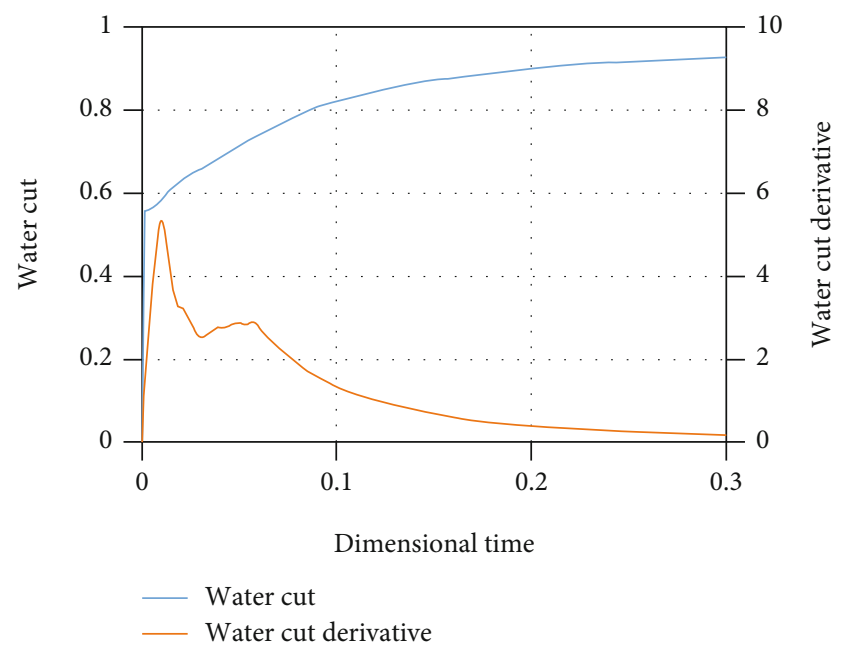

Figure 6: Water cut and its derivative change curve with dimensionless time in the presence of high-water-consumption zone.

where $V$ is the water storage capacity around the injected well, $r$ is the radius of injection water gathering area, $h$ is the effective formation thickness, $\varphi$ is the porosity, and $\gamma$ is the dispersion coefficient.

Taking a typical well as an example (Figure 4), the well test interpretation model for low-permeability reservoir is adopted to interpret the well. The radius of holding water is $35 \mathrm{~m}$; combined with the reservoir physical parameters, the containment water of the well can be calculated by volumetric method as $23,000 \mathrm{~m}^{3}$.

\subsection{Evaluation Method of Water Injection Direction and} Water Injection Utilization Ratio in High-Water-Content Reservoir. Based on the well test theory [10-15], the derivative curve characteristics of the oil-water ratio can be obtained. According to the characteristics, the direction of the injected water flow direction and the water injection utilization ratio can be judged.

During development and production, a large number of production dynamic data of injection-production wells can 


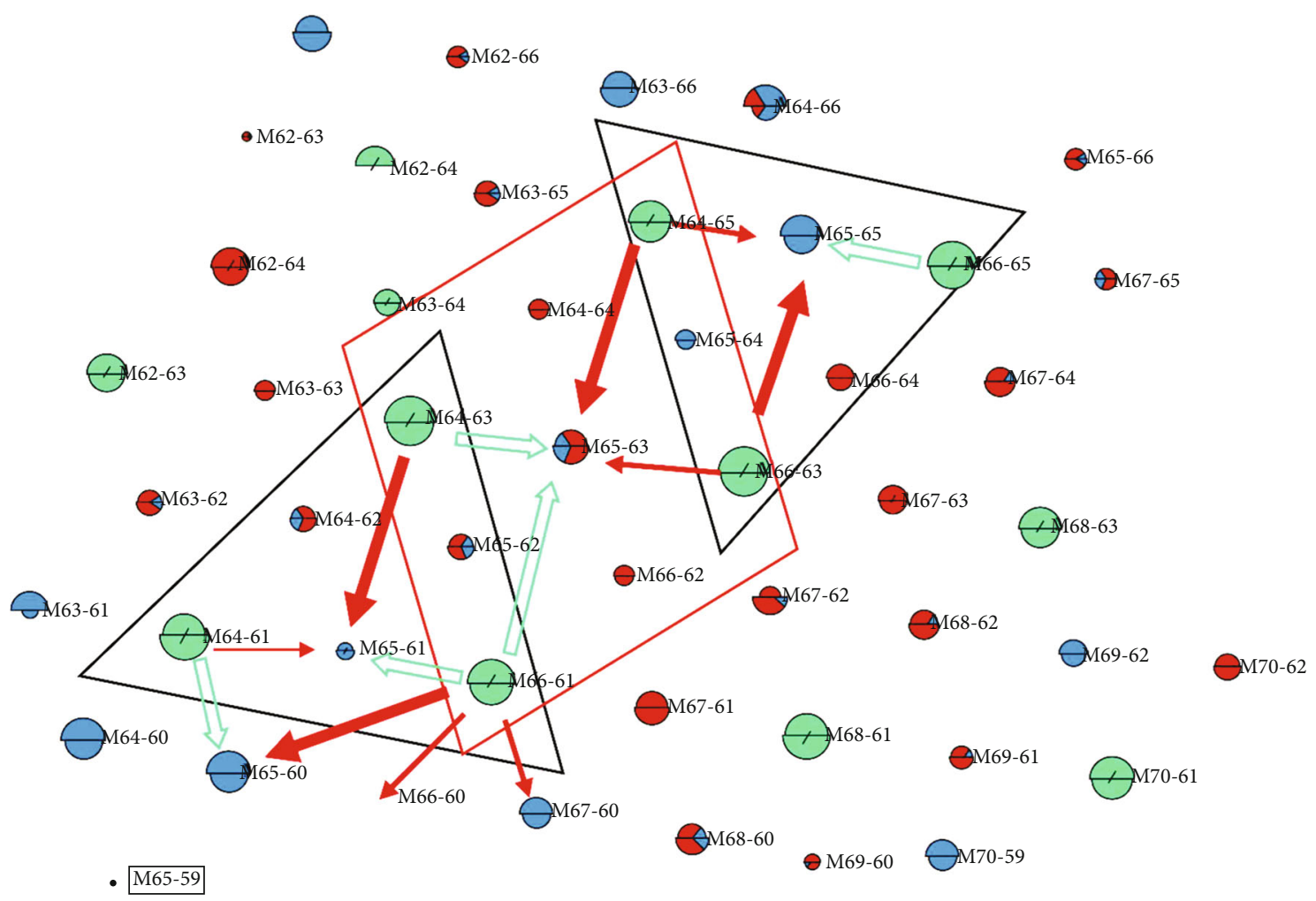

FIGURE 7: Analysis of channeling direction and channeling ratio of typical well groups (red indicates the direction of channeling, the width of the red arrow reflects the proportion of channeling flow, and the green arrow indicates that there is no channeling.)

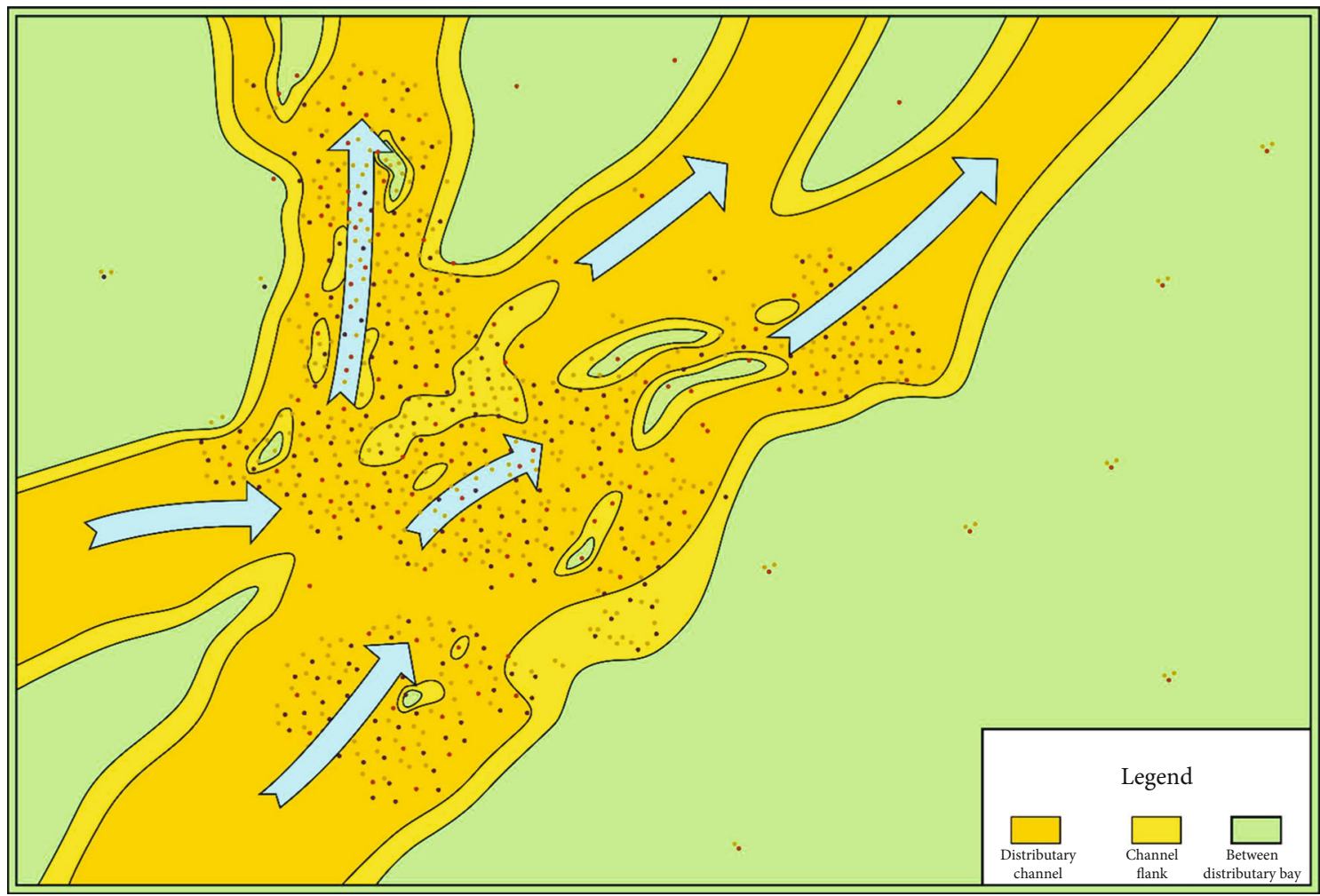

FIGURE 8: Sedimentary microfacies characteristics of the reservoir. 


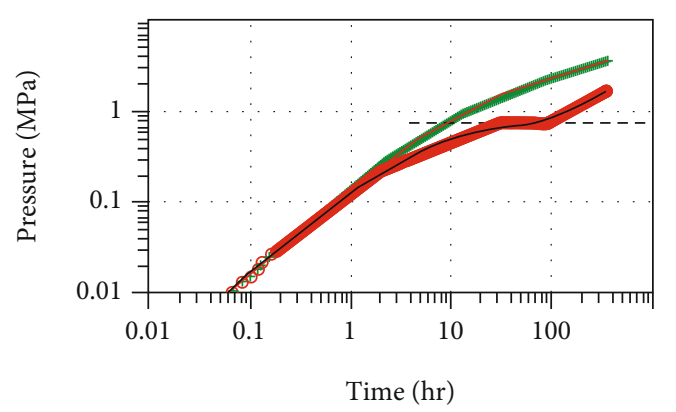

Figure 9: Pressure drop curve characteristics of typical well test, well A.

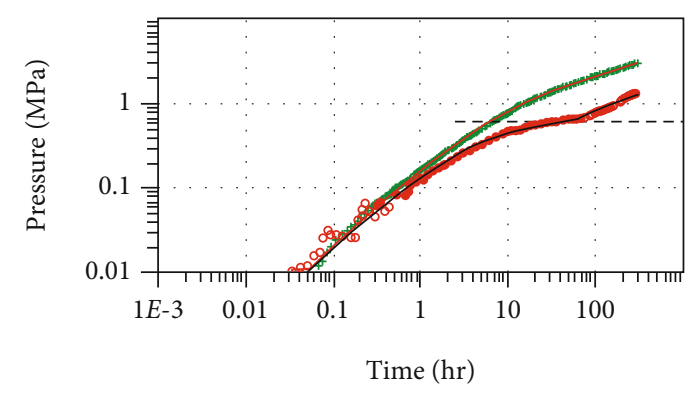

FIGURE 10: Pressure drop curve characteristics of typical well test, well B.

be obtained, such as injection amount and water cut. In order to facilitate the research, dimensionless time $t_{D}$ is introduced.

$$
t_{D}=\frac{q_{i} t}{A \phi h}
$$

where $q_{i}$ is the injection well injection rate, $\mathrm{m}^{3} / \mathrm{d} ; t$ is the injection well accumulates injection time, $\mathrm{d} ; A$ is the reservoir area, $\mathrm{m}^{2} ; h$ is the average reservoir thickness, $\mathrm{m}$.

Dimensionless time $t_{D}$ is obtained by $T$, which not only introduces time $T$ but also considers the injection amount and reservoir volume of the injection well. Then, derivative of water cut can be obtained. The definition of derivative of water cut of production well is as follows:

$$
f_{w}^{\prime}\left(t_{D}\right)=\frac{d f_{w}}{d t_{D}}
$$

where $f_{w}$ is the water cut of production well, $t_{D}$ is the dimensional time, and $f_{w}^{\prime}\left(t_{D}\right)$ is the derivative of water cut of production well with respect to dimensionless time.

When there is no interference between injection and production wells, the dimensionless derivative curve of water cut is characterized by a single peak; when there is interference between injection and production wells, the dimensionless derivative curve of water cut is characterized by a double peak, as shown in Figures 5 and 6. According to this feature, it is possible to judge whether there is channeling between injection-production wells and determine the water flow direction.

\section{Application Instance}

Taking a reservoir in Changqing as an example, the average permeability of this reservoir is $0.8 \mathrm{mD}$, which is an ultralow-permeability reservoir. The current injectionproduction ratio is 5 , and the average reservoir pressure remains at the same level as the original formation pressure, which indicated that $80 \%$ of the injected water is not effective, so it is urgent to determine the direction of water injection and guide the adjustment of water injection development.

\subsection{Analysis of Water Injection Flow Direction and Water} Injection Utilization Ratio. This area is a reservoir with high water cut and low permeability. The formation pressure is maintained at a high level. It is necessary to determine the direction of water flow. The established identification method was used to evaluate the area, and the results are shown in Figure 7. In order to verify the reliability of the evaluation results, the tracer method was used for monitoring. The tracer test results were very consistent with the evaluation results which indicate that the evaluation method had good reliability.

The above methods are used to analyze the current interfacial flow direction and flow rate of the injected water in this area. The evaluation results show that $45 \%$ of the injected water has interfacial flow. The direction of the injected water interfacial flow in this area has a good corresponding characteristic with the sedimentary microfacies. The sedimentary characteristics of this area are the main inducement of the interfacial flow in this area, rather than the microfracture previously believed, as shown in Figure 8.

3.2. The Evaluation of Holding Water Volume. At present, the cumulative injection-production ratio in the West 34 well area and the West 25 well area is 4.38 , and the actual average formation pressure remains at $100 \%$, that is, about $70 \%$ of the injected water is not effectively utilized. $75 \%$ of injection wells (Figures 9 and 10) in this area are characterized by a composite reservoir and meet the following rules: (1) The average pressure drop test time is about 15 days, but the pressure drop is about $2 \mathrm{MPa}$ and the pressure drop is small. (2) Before the test, the average wellhead oil pressure was $18 \mathrm{MPa}$, the formation injection pressure was above $38 \mathrm{MPa}$, and the injection pressure was very high, but the injection volume decreased. (3) Well test curve shows the characteristics of composite reservoir. According to the previous understanding, we can judge the characteristics of water holding in wells in this area.

According to the data collected, the average cumulative injection volume per well in this area is $116,400 \mathrm{~m}^{3}$, and about $20 \%$ of the injected water is not effectively swept. If a well is drained at a rate of $100 \mathrm{~m}^{3} / \mathrm{d}$, it will drain for 200 days.

\section{Conclusion}

(1) For the high-water-cut reservoirs, the evaluation method of water injection destination and water injection utilization rate was established. The reliability of the method was verified by comparing with the 
tracer test results. This method only needs to produce dynamic data to judge the direction of channeling and the proportion of channeling

(2) For reservoirs with high injection-production ratio and low formation pressure maintenance level, a well test interpretation model based on well testing is established, and the judgment standard for water holding is determined. Well test analysis method can be used to determine the holding volume of the injected water

(3) By using the above methods on a typical reservoir, the injected water flow direction and the holding water showed that about $45 \%$ of the injected water had channeling and the water injection was ineffective. In the water holding area, about $20 \%$ of the injected water is held near the bottom of the well. The above results can provide data reference for the adjustment of water flooding in this reservoir

\section{Data Availability}

The data used to support the findings of this study are available from the corresponding author upon request.

\section{Conflicts of Interest}

The authors declare that they have no conflicts of interest.

\section{Acknowledgments}

This work received funding supports from the Science Foundation of China University of Petroleum, Beijing (2462018YJRC032 and 2462020YXZZ027) and the National Major Project of China (2017ZX05030002-005).

\section{References}

[1] M. K. Fisher, C. A. Wright, B. M. Davidson et al., "Integrating fracture-mapping technologies to improve stimulations in the Barnett shale," in SPE Annual Technical Conference and Exhibition, San Antonio, Texas, USA, 2002.

[2] M. J. Mayerhofer, E. P. Lolon, N. R. Warpinski, C. L. Cipolla, D. Walser, and C. M. Rightmire, "What is stimulated rock volume?," in Paper SPE 119890 presented at SPE Shale Gas Production Conference, Fort Worth, Texas, 2008.

[3] H. Wang, X. Liao, and X. Zhao, "Research progress of reservoir volume reconstruction simulation technology for unconventional reservoirs," Special Reservoirs, vol. 21, no. 2, pp. 8-15+151, 2014.

[4] C. L. Cipolla, E. P. Lolon, J. C. Erdle, and B. Rubin, "Reservoir modeling in shale-gas reservoirs," SPE Reservoir Evaluation \& Engineering, vol. 13, no. 4, pp. 638-653, 2010.

[5] C. L. Cipolla, "Modeling production and evaluating fracture performance in unconventional gas reservoirs," Journal of Petroleum Technology, vol. 61, no. 9, pp. 84-90, 2009.

[6] A. K. Harikesavanallur, F. Deimbacher, and M. V. Crick, "Volumetric fracture modeling approach (VFMA): incorporating microseismic data in the simulation of shale gas reservoirs," in Proceedings of the SPE Annual Technical Conference and Exhibition 2010, Florence, Italy, 2010.

[7] G. Zhao, "A simplified engineering model integrated stimulated reservoir volume (SRV) and tight formation characterization with multistage fractured horizontal wells," in SPE Canadian Unconventional Resources Conference 2012, Calgary, Alberta, Canada, 2012.

[8] B. Suliman, R. Meek, R. Hull, H. Bello, D. Portis, and P. Richmond, "Variable stimulated reservoir volume (SRV) simulation: Eagle Ford shale case study, Denver, Colorado, USA, 2013.

[9] C. M. Du, X. Zhang, L. Zhan et al., "Modeling hydraulic fracturing induced fracture networks in shale gas reservoirs as a dual porosity system," in International Oil and Gas Conference and Exhibition in China, Beijing, China, 2010.

[10] T. W. Teklu, J. Akinboyewa, N. Alharthy et al., "Pressure and rate analysis of fractured low permeability gas reservoirs: numerical and analytical dual-porosity models," in SPE Unconventional Gas Conference and Exhibition 2013, Muscat, Oman, 2013.

[11] X. Liao, X. Chen, and X. Zhao, "Analysis of volumetric fracturing well pressure characteristics in low permeability reservoirs," Science and Technology Guide, vol. 34, no. 7, pp. 117$122,2016$.

[12] H. Wang, Research and Application of Dynamic Inversion Technology for Volume Fractured Well in Low Permeability Reservoir, China University of Petroleum (Beijing), Beijing, 2015.

[13] X. Liu, C. Tian, and L. Jiang, "Evaluation model of volumetric fracturing for vertical wells in tight reservoirs," Journal of Northeast Petroleum University, vol. 38, no. 1, pp. 91-96, 2014.

[14] C. L. Cipolla, T. Fitzpatrick, and M. J. Williams, "Seismic-tosimulation for unconventional reservoir development," in SPE 146876-MS presented at the SPE Reservoir Characterization and Simulation Conference and Exhibition, Abu Dhabi, UAE, 2011.

[15] M. H. Hui, B. T. Mallison, M. H. Fyrozjaee, and W. Narr, "The upscaling of discrete fracture models for faster, coarse-scale simulations of IOR and EOR processes for fractured reservoirs," in SPE Annual Technical Conference and Exhibition, New Orleans, Louisiana, USA, 2013. 